Acta Universitatis Wratislaviensis No 3836

Anglica Wratislaviensia LVI, Wrocław 2018

DOI: 10.19195/0301-7966.56.20

\author{
Katarzyna Więckowska \\ ORCID: 0000-0003-3408-3695 \\ Nicolaus Copernicus University, Torun \\ klew@umk.pl
}

\title{
Between and Beyond Intersex and Transgender Studies: A Review of Transgender and Intersex: Theoretical, Practical, and Artistic Perspectives, Stefan Horlacher (ed.), New York: Palgrave Macmillan, 2016
}

\begin{abstract}
This review assesses Transgender and Intersex: Theoretical, Practical, and Artistic Perspectives (2016), edited by Stefan Horlacher. Inspired by the international and interdisciplinary conference on "Transgender and Intersex in the Arts, Science and Society" that was held in 2012 in Dresden and that gathered researchers, activists, and artists working in transgender and intersex studies, the collection aims at mapping potential alliances between intersex and transgender positions, while acknowledging that the interests of transgender and intersex communities and researchers may be conflicting, if not at times contradictory. The volume adopts a non-hierarchical, multiperspectival, and interdisciplinary approach to examine a variety of issues related to gender variance and politics of recognition. Accordingly, the articles focus on those processes and texts that have played major roles in deconstructing and reconstructing gender identities during the late twentieth and early twenty-first centuries, and present analyses of legal and sociopolitical issues, theoretical perspectives and dilemmas, and literary and visual representations. The diverse topics and perspectives embrace the ethical framework of human rights, so as to inquire into the ways through which the lives and representations of marginalized groups can be improved.
\end{abstract}

Keywords: transgender studies, intersex studies, identity, gender theory, alliances, transgender and intersex literary and visual representations

Transgender studies is a relatively recent field of research which emerged in the early 1990s and by the end of the century became a fully developed discipline. Between 1995 and 2005, as Susan Stryker states, "'transgender' moved from the clinics to the streets [...], and from representation to reality" (2006: 2), creating not only new forms of entertainment, but also new challenges to the fields of politics and law, and a new academic discipline (Whittle 2006: xi). In the first Transgender 
Studies Reader, compiled by Susan Stryker and Stephen Whittle in 2006, the new area of research is described as first of all interdisciplinary, deploying the methodological frameworks of "the social sciences and psychology, the physical and life sciences, and the humanities and arts" in order to engage with the complex connections between material conditions and representational practices of transgender subjects (Stryker 2006: 3). In the foreword to the Reader, Whittle stresses the interdependencies between transgender studies and community activism, and situates trans studies in the broader critical framework by describing it as "a linking of feminist and queer theory" (2006: xii). In the first decades of the twenty-first century, critical and public fascination with "trans issues" persists, as demonstrated, respectively, by the continuing development of transgender studies and by the increasing number of books dealing with transgender themes, together contributing to the "publishing boom" in transgender fiction and criticism (Love 2011: 150).

Significantly, the early 1990s saw also the emergence of public and critical interest in intersex subjects. With the founding of the Intersex Society of North America (ISNA) in 1993, the word "intersex" entered public discourse, leading to activism and the politicization of intersex identities during the mid-1990s (Chase 2000: 437). Between the 1990s and the second decade of the twenty-first century, the term has been reclaimed from the medical usage linked with pathologization and has undergone a number of transformations, first into a sign of a politicized and oppositional identity in the 1990s, an expression linked to transnational human rights in the 2000s, and finally into an outdated label to be replaced in the $2010 \mathrm{~s}$ by the term "disorders of sex development" (Rubin 2017: 11), reframed by some intersex people and communities into "diversity of sex development" (Costello 2016: 85 ). The rise of political activism from the 1990s onwards has been paralleled by the growth in the number of personal accounts and life stories of intersexual people (Amato 2016: 20) ${ }^{1}$, and by the recognition of the critical potential of "intersex" as a category which, as David Rubin convincingly argues, "challenges us to rethink and rearticulate the biopolitics and geopolitics of sex, gender, race, and nation in new ways" (2017: 8). Despite these developments, however, critical intersex studies at the beginning of the twenty-first century remains an "emergent and still not clearly delineated branch" (Amato 2016: 21), with a troubled and troubling relation to mainstream gender theories, in particular to transgender studies. The lack of critical analysis has been noted by a number of critics, including Viola Amato, who writes about the scarce academic research on contemporary intersex (identity) politics and the even scarcer research into cultural representations of

${ }^{1}$ My account of the development of intersex criticism and literature imposes a chronological frame on events and phenomena which frequently occurred simultaneously and in a much more chaotic manner, succinctly summarized in Almato's statement that "the several narratives on intersex cannot be understood in a (strictly) chronological order, but as simultaneously progressing and interreferential movements, as continuing processes of (re)affirmation, challenging and resignification" (2016: 14). 
intersex individuals and intersex themes (21-22), and Rubin, who explicitly states that "intersex matters remain underaddressed in contemporary critical accounts of the politics of difference" (3).

Transgender and Intersex: Theoretical, Practical, and Artistic Perspectives (2016), edited by Stefan Horlacher, is a timely contribution to the fields of both transgender and intersex studies which proposes to focus on the commonalities and convergences between these two areas of research rather than opposing them, as is usually the case. The aim of the collection is to open a new perspective for analyzing and theorizing these positions, outlined in the introductory article by Stefan Horlacher. Horlacher convincingly argues for the necessity to use approaches that are intersectional and trans- and interdisciplinary in order to analyze and uncover the multiple ways in which gender identities both influence and are influenced by various socio-cultural, historical, political, and biological factors. The opening article beings with a comprehensive and incisive overview of transgender and intersex positions, delineating their respective goals and strategies, as well as divergences, and working towards a shared perspective that could be used to inquire into the methods and effects of policing the boundaries between sex and gender exercised by various discursive domains - medicine, biology, the law, or society. Accordingly, the articles collected in the volume combine humanistic and social science approaches to examine law, sports, literature, film, and photography, and to bridge the gap between the abstract and the practical - between knowledge, theory, philosophy, art, life experience, and activism - with the overall aim to construct a non-hierarchical, multiperspective approach that exceeds the limitations of contemporary gender research (Horlacher 2016: 3). Intersectionality and interdisciplinarity appear as key aspects of the approach, since it is the examination of various elements and spheres and the adoption of various perspectives that not only allow for presenting the complexity of the discussed issues, but also - and importantly - outline the possibilities of a viable life.

The non-hierarchical, multiperspectival approach determines the way in which the volume is organized, with specific articles employing different perspectives to address different issues, or applying different perspectives to discuss the same issue. The use of various approaches is reflected on the level of language, where the meaning of such terms as "trans" or "inter" is questioned, destabilized, and negotiated, thereby placing the possibility of change at the very heart of the project. ${ }^{2}$ All the articles focus on processes and representations that have played major roles in deconstructing and reconstructing gender identities during the late twentieth and early twenty-first centuries, proceeding from analyses of legal and sociopolitical issues, through discussions of theoretical perspectives and dilemmas, to readings of literary texts, films, and photographs (Horlacher 2016: 16).

${ }^{2}$ For the sake of clarity, I have decided to use a uniform terminology to describe the volume as a whole. At the same time, however, I would like to stress the fact that I consider the process of (linguistic) re-signification to be one of the major aims and achievements of the book. 
The factor unifying the various explorations is the search for potential alliances between the transgender and intersex perspectives, although the tensions that exist between these positions are acknowledged and addressed. Thus, the first two articles focus on legal questions with regard to transgender and intersex subjects and discuss the global LGBT European law and UK legislation on sport, respectively. The following three chapters continue the exploration of transgender and intersex positions, inquiring into the similarities between intersex and trans communities, the (possibly emancipatory) uses of body and mind essentialisms, and the normative and normativizing reproductive procedures. The worldwide influence of the transgender framework is discussed in the next chapter, which considers the impact of transgenderism on global definitions of gender and sexuality, and analyses the depiction of gender diversity in three recent films. The section dedicated to art begins with a presentation of the work of Del LaGrace Volcano, a gender variant visual artist who explores the connections between body and gender/sexual identity (Horlacher 2016: xiv). The discussion of the possibilities of an inter-position is continued in the next article, which looks into science, law, and the arts to investigate the "either-or" attitude governing human mind and action, and to outline the possibilities for resisting it. The last two articles offer examinations of trans and intersex literature and film, focusing on politics of representation, intelligibility, and authorial and critical responsibility. By concluding with a focus on cultural representations, Transgender and Intersex draws the readers' attention to the pivotal role the arts play in providing a cultural repository through which new identities can be imagined and lived, or, as Horlacher puts it, in providing knowledge that is predominantly "a knowledge about and for living different lives that renders Uberleben (survival) possible" (13; emphasis in the original).

The examination of the legal status of trans and intersex individuals begins with an analysis of selected developments in European jurisdiction and the new "rule of law" that has contributed to the recognition of the rights of LGTB people. In "Queer Europe: New Normative Values for Global LGBT Law," Stephen Whittle and Lewis Turner trace the significance of the sexed body to European laws and states, and document the shift toward gender neutrality that they claim has been taking place within the past 20 years. As they argue, recent European legislation, such as the Gender Recognition Act 2004, has made the body's sex redundant as a taxonomical tool (41). Whittle and Turner emphasise the ethical approach adopted by EU institutions - which are both normative and ethical (45) - and contrast it with the policies of particular nation states, which impede the shift to gender neutrality and become the actual source of problems facing LGBT people in Europe. The authors identify the difference between the European Union and the nation states, or between the theory and the practice of Europe (46), as the reason why homophobia and transphobia continue to be significant problems (51). Additionally, Whittle and Turner note that the development of "a queer European sensibility" (46) visible in law, economy, and the arts has not been paralleled by 
the recognition of intersex people, so that, "[s]adly, Europe remains mute on the question of intersex rights" (57).

In "Fear, Loathing, and Empty Gestures: UK Legislation on Sport and the Transgender Participant," David McArdle looks into the restrictions on sports participation of transgender people, providing an overview of gender verification policies and the problems created by incompatible international and national regulations. McArdle closely examines the infamous Section 19 of the United Kingdom's Gender Recognition Act 2004, which gave "a body responsible for regulating the participation of persons as competitors in an event or events involving a gender-affected sport" the right to "prohibit or restrict the participation as competitors in the event or events of persons whose gender has become the acquired gender" (76). Section 19 was repealed by the Equality Act 2010, but, as the author argues, it should be seen as symptomatic of "sport's difficulty in getting beyond what 'common sense' tells us about sport, sex and gender" (78). Ultimately, McArdle states, Section 19 "reinforces the perception that natural, biological qualities determine social practices" (78), and thus exemplifies other regulatory "empty gestures" that performatively constitute transgender bodies in sports as other. In the end, such laws and regulations demonstrate that "transgender participation in sports is problematic because sports field's sacrosanct perceptions of what is 'fair' or 'appropriate' cannot easily be reconciled with the social, medical, and surgical realities of transgender status" (McArdle 2016: 69).

While the possibilities of strategic alliances between transgender and intersex positions are a recurrent motif in the book, they are the major focus of Cary Gabriel Costello's "Intersex and Trans* Communities: Commonalities and Tensions." Based on interviews with members of online support groups, Costello's detailed and revealing discussion of the divisions and alliances between and within intersex and trans communities starts from locating the common ground between them in their non-conforming relation to the sex/gender binary. The article highlights the commonalities between trans and intersex groups, such as the pressure to be normalized, the sense of stigma, or the desire for and lack of bodily autonomy, and points to inter- and intracommunity tensions and divisions that the author maps along the disorder and identity frameworks (98). Costello's detailed analysis of the similarities and differences between the groups complicates the notion of community as a coherent and closed entity, and locates the solution to the interand intracommunity tensions in adopting the identity framework which allows for "agitat[ing] for civil rights protection against discrimination" (107).

Similarly to Costello's article, Sebastian Jansen's "Transgender and Intersex: Unavoidable Essentialism and the Normative Struggle for Recognition" examines the possibilities for theoretical and activist alliances between transgender and intersex studies. Unlike Costello, however, Jansen does not propose to destabilize or overthrow the binary gender system because, as he claims, "from a purely logical point of view, fighting binary oppositions is a paradoxical, self-defeating move. The 
very fight itself establishes a binary opposition" (131). Instead, Jansen proposes to work for "intersex and trans people's recognition and self-determination" (116), and discusses the ways in which normative/normativizing tools can be used in the fight for recognition. Accordingly, the author focuses on two kinds of essentialism that recur in transgender and intersex communities: body essentialism, in which the body provides the basis for constructing an identity and which prevails in intersex communities, and mind essentialism, dominating in transgender groups, where a body is constructed on the basis of an inner-self or identity (121). These two kinds of essentialism, as Jansen argues, somewhat provocatively, may be productively used to gain "a voice in the social-political arena" since they give individuals the grounds for self-affirmation and provide the position from which one can "defend one's own self-categorization and the right to it" rather than merely "destabilize categories and ensure freedom from them" (136; emphasis in the original).

Jansen's dismissal of deconstruction as a non-productive critical method is juxtaposed against the turn to "the threefold gesture of deconstruction - de-naturalization, de- / re-institutionalization, and increase in complexity" (2016: 147) which Nadyne Stritzke and Elisa Scaramuzza use to critique the prevalent model of binary gendered heterosexual procreation and the practices of repronormativity that reinforce it. "Trans, Intersex, and the Question of Pregnancy: Beyond Repronormative Reproduction" approaches reproduction as "not a 'natural' human condition" and "not obligatorily sex binary," and argues that the dominant concepts of reproduction are effects of "discursively produced ways of speaking" (Stritzke and Scaramuzza 2016: 144-145). Hence the need to analyze reproductive differences and to develop a vocabulary that might adequately describe them - as Stritzke and Scaramuzza claim, "only in ongoing negotiable communicative processes is it possible to reformulate our socio-cultural practices" (157). Their analysis of contemporary reproductive procedures and discourses shows that a new politics of reproduction has emerged, especially in relation to trans people and trans pregnancies, but that intersex bodies and individuals remain invisible "not only in mainstream repronormative discourses but also in trans* reproductive political and academic petitions" (Stritzke and Scaramuzza 2016: 151).

Jack Halberstam's contribution to the volume focuses on transgenderism and the effects of adopting a parochial, U.S.-based perspective to discuss traditional gendering, queer communities, global definitions of gender and sexuality. "Transgender in a Global Frame" begins with a careful reading of Judith Butler's work, delineating the changes in perspective from the non-unified, non-teleological politics of Gender Trouble (1990) to the ethical postulates of Undoing Gender (2004), and ends with an image of the anthropocene as the time when, according to the author, the question of survival becomes more important than that of recognition of rights (185). Halberstam's survey of global transgenderism finishes with the analysis of three films which, by focusing on such issues as gender, sexuality, race, migration, labor, exile, and language, approach "transgenderism as part of a 
complex matrix of identification rather than as a singular feature of embodiment," thereby expanding the framework of what may make a life livable (180).

"INTER *me: An Inter-Locution on the Body in Photography" begins the section of articles dedicated to art and, as Horlacher puts it in the introduction to the volume, is itself a work of art (19), as it includes reproductions of photographs by Del LaGrace Volcano, in particular the latest series, INTER*me. The text is framed as a conversation between Volcano - a photographer, "part-time gender terrorist," and "intentional mutation" (189) - Jay Prosser, and Eliza Steinbock on the questions of and relations between embodiment, identity, sexuality, language, representation, Inter*subjectivity ${ }^{3}$, parenting, and aging, to name the most important topics of the "inter-locution." The key motifs of Volcano's art, as well as of the article, are interruption, betweenness, metamorphosis, and the interstitial that are perhaps best encapsulated by the artist's use of "herm" as "a noun and pronoun to self-name" and to thereby reclaim "from medical and mythical discourse an ambiguity that interrupts gender binaries" (223).

Dualisms, and in particular gender binaries, return as the topic of discussion in Michael Gronenberg's "Hermaphrodite's Voice: Dealing with the Either-Or Attitude in Science, Law, and the Arts," which argues that the disjunctive logic that dominates human mind and action is the primary cause of the resistance to accept inter- and transgender persons (244). Examining the "either-or" attitude, Gronenberg looks to philosophy, art, especially sculpture or photography, and the imaginary realm as creating possibilities for moving beyond dualisms. In theory and research, such potential can be found in "transdisciplinarity," in which disciplines are transformed through interaction and academic research is transcended "by integrating life-world experience and its concrete and situated knowledge in the research process" (230). In the end, as Gronenberg argues, the alternative to the "either-or" attitude does not lie in the refusal of binaries, but in the adoption of an inclusive point of view which "respects many people's wish of being on one side or the other and respects necessity, in many domains, of thinking and acting in binaries and opposites, but without indulging in them, by taking a critical distance and by considering further possibilities" (244).

Mirjam M. Frotscher's "On the Intelligibility of Trans* and Intersex Characters in Contemporary British and American Fiction" examines the literary representations of the possibilities and costs of disrupting the "either-or" logic. The key concept in the analysis is that of intelligibility, which, following Judith Butler, Frotscher describes as what can be "life-sustaining" but also "life-threatening" for those ambiguous bodies and subjects that cannot be represented in language (255). As Frotscher argues, because literature can represent those lives that have been deemed unintelligible, examining the ways in which trans- and intersexual characters are represented is no

3 In the article, an asterisk is added to the terms "trans" and "inter" in order "to make "trans' a more inclusive term" and to turn "inter" into "a multivalent term reflective of its multiform community" (223). 
longer merely an aesthetic concern, but also a political one (256). Accordingly, the author analyses the transgender classic Stone Butch Blues (1993) by Leslie Feinberg, Trumpet (1998) by Jackie Kay, and the Pulitzer Prize-winning novel Middlesex (2000) by Jeffrey Eugenides, and explores the various modes of representation used to portray marginalized characters and topics. Importantly, the analysis is framed by the question of responsibility - of the writers for the characters to whom they grant intelligibility or not, and of the readers, including literary critics, who should "be held accountable for the worlds they create" (270).

The volume closes with John Philips's analysis of the modes of representation of transgender characters in two films: the American Boys Don't Cry (1999) and the French Tomboy (2011). Drawing on queer theory, in particular the work of Judith Butler, and Freudian and Jungian ideas, Philips explores the means through which the films present a plea for social recognition, while at the same time working to domesticate - or "evacuate" - the otherness of transsexuality (291). "Boys Don't Cry and Tomboy: A Comparative Analysis" concludes with the statement that both films do not show transgender characters "with unqualified positivity," thereby unmasking a lack in the existing classifications of gender and sexuality, and calling for new categories that go beyond male and female (291).

In the introduction to Transgender and Intersex, Stefan Horlacher writes that the non-hierarchical, multiperspectival approach adopted in the book aims at overcoming "the limitations of sex and gender research [...] by asking how transgender and intersex issues are negotiated and conceptualized from a variety of points of view" (3). This is a goal that the collection achieves, exploring positions and possibilities beyond and between the already established ones. Importantly, the book bridges the gap between the abstract and the practical - between knowledge, theory, art, real life, and activism - not only through adopting various analytical tools and positions, but also by presenting authors who are artists and critics, activists and scholars, and who represent a panoply of disciplines. Additionally, while the decision to combine articles representing different, sometimes contradictory positions risks the danger of leaving the reader confused, it seems a risk worth taking, if only because of its transformative potential, especially with regard to the links between transgender and intersex studies. In effect, the volume offers the kind of critique of gender norms and research methodologies that Judith Butler - a persistent, though contested presence in the volume - describes as one that "must be situated within the context of lives as they are lived and must be guided by the question of what maximizes the possibilities for a livable life, what minimizes the possibility of unbearable life or, indeed, social or literal death" (2004: 8). Transgender and Intersex places theoretical considerations in the context of real lives and examines their representations in theory and art; significantly, it does so by adopting positions that evade the dangers of discursive and critical colonization, and that, describing the affinities between transgender and intersex studies, manage to sustain the differences between them. 


\section{References}

Amato, V. 2016. Intersex Narratives: Shifts in the Representation of Intersex Lives in North American Literature and Popular Culture. Bielefeld: Transcript Verlag.

Butler, J. 2004. Undoing Gender. New York: Routledge.

Chase, Ch. 2000. "Hermaphroditism.” In: Beynon, J., D. Eisner, and G.E. Haggerty (eds.). Gay Histories and Cultures. New York: Garland. 436-437.

Horlacher, S. (ed.). 2016. Transgender and Intersex: Theoretical, Practical, and Artistic Perspectives. New York: Palgrave Macmillan.

Love, H. 2010. "Transgender Fiction and Politics." In: Stevens, H. (ed.). The Cambridge Companion to Lesbian and Gay Writing. Cambridge: Cambridge University Press. 148-163.

Rubin, D. 2017. Intersex Matters: Biomedical Embodiment, Gender Regulation, and Transnational Activism. New York: State University of New York Press.

Stryker, S. 2006. “(De)Subjugated Knowledge: An Introduction to Transgender Studies.” In: Stryker, S. and S. Whittle (eds.). The Transgender Studies Reader. New York-London: Routledge. $1-17$.

Whittle, S. 2006. "Foreword.” In: Stryker, S. and S. Whittle (eds.). The Transgender Studies Reader. New York-London: Routledge. xi-xvi. 